\title{
Las clases de yoga y de estiramiento son igualmente efectivas para aliviar la lumbalgia crónica
}

\author{
Yoga and stretching classes are equally effective in alleviating chronic low back pain
}

Sherman K. y col. Arch Intern Med. Oct 2011;171(22):2019-2026.

\section{Objetivos}

Comparar la eficacia de tomar clases de yoga, clases de estiramiento (en inglés, stretching) o de recibir información sobre autocuidado para aliviar la lumbalgia crónica (LC).

\section{Diseño, Lugar y Pacientes}

Ensayo aleatorizado y controlado realizado en EE.UU. Se reclutaron pacientes que consultaron por LC en ámbitos atención primaria, entre junio de 2007 y mayo del 2009. Se excluyeron aquellos individuos que presentaban dolor por causas específicas (espondilolistesis, fractura vertebral, metástasis, etc.), dolor agudo, o dolor de baja intensidad en el momento de la inclusión. Fueron elegidos 228 adultos, los cuales se dividieron en tres ramas (2:2:1): yoga, estiramiento, y autocuidado.

\section{Intervención}

Los grupos asignados a clases de yoga $(n=92)$ y clases de estiramiento $(n=91)$ recibían 12 clases de 75 minutos de duración, una vez por semana, y se les solicitaba además que practiquen 20 minutos diarios los días que no asistían a clases siguiendo la guía de folletos, CD o DVDs ad hoc. Las clases de yoga (viniyoga) y stretching eran impartidas por instructores y fisioterapeutas con experiencia, respectivamente. El grupo autocuidado $(n=45)$ recibió información en forma de libro de autoayuda, el cual contenía información sobre causas, ejercicios y modificaciones del estilo de vida para aliviar la LC.

\section{Medición de resultados principales}

Se utilizó el cuestionario de discapacidad de Roland-Morris (de 23 ítems) y una escala auto-administrada (0 a 10 puntos) de molestias provocados por LC. La medición se realizo mediante entrevistas telefónicas al inicio, 6, 12 y 26 semanas. Se tomó la evaluación a las 12 semanas como resultado principal. El análisis fue por intención de tratar.

\section{Resultados principales}

A las 12 semanas el grupo yoga resulto ser más efectivo que el grupo autocuidado. Entre yoga y estiramiento no se encontraron diferencias significativas (ver tabla 1).

Tabla 1: Diferencias en funcionalidad y síntomas entre grupos de pacientes con lumbalgia crónica evaluados a las doce semanas.

\begin{tabular}{l|c|c|c}
\multirow{2}{*}{$\begin{array}{l}\text { Instrumento } \\
\text { de evaluación }\end{array}$} & \multicolumn{3}{|c}{ Diferencia entre los grupos (IC 95\%)* } \\
\cline { 2 - 4 } $\begin{array}{l}\text { Yoga vs } \\
\text { autocuidado }\end{array}$ & $\begin{array}{c}\text { Estiramiento vs } \\
\text { autocuidado }\end{array}$ & $\begin{array}{c}\text { Yoga vs } \\
\text { estiramiento }\end{array}$ \\
$\begin{array}{l}\text { Cuestionario } \\
\text { Roland Morris }\end{array}$ & $-2,48(-3,70$ a $-1,26)$ & $-2,18(-3,37$ a $-1,00)$ & $-0,30(-1,33$ a 0,74$)$ \\
\hline $\begin{array}{l}\text { Escala } \\
\text { auto-administrada } \\
\text { de molestias }\end{array}$ & $-1,07(-1,75$ a $-0,41)$ & $-0,59(-1,30$ a 0,11$)$ & $-0,49(-1,06$ a 0,08$)$ \\
\hline
\end{tabular}

*Ajustado por: puntaje basal de cuestionario Roland Morris y escala auto-administrada de molestia por lumbalgia crónica, sexo, edad, índice de masa corporal, días de dolor lumbar en los últimos seis meses, dolor con irradiación al miembro inferior, exposición a trabajos de esfuerzo.

\section{Conclusiones}

Las clases de yoga fueron más efectivas que los libros de autoayuda, pero no más efectivas que las clases de estiramientos para mejorar la función y reducir los síntomas debido a la LC. Este beneficio se mantiene al menos durante algunos meses.

Fuente de financiamiento: National Center for Complementary and Alternative Medicine (NCCAM)

\section{Comentario}

La LC es motivo de consulta frecuente en atención primaria ${ }^{1}$, produce discapacidad y es una de las causas principales de ausentismo laboral. Más del $85 \%$ es de causa inespecífica ${ }^{2}$. Uno de los principios básicos para manejar la LC es indicar al paciente un programa de ejercicios activos en forma regular para aliviar el dolor. Varios estudios avalan esta indicación. Recientemente se han realizado investigaciones sobre las clases de yoga y estiramiento que mostraron ser beneficiosos $^{3}$ pero con limitaciones metodológicas, como por ejemplo, pequeña muestra de pacientes, alto número de bajas y falta del detalle del tipo de yoga administrado ${ }^{4}$. Este estudio tiene como fortaleza el tamaño de la muestra, la escasa pér- dida de pacientes y el detalle completo de cada intervención, que mejora su validez externa. Como limitante, es una población selecta de un solo lugar, bien educada y funcional y no tiene un seguimiento más allá de las 26 semanas.

Conclusiones de la comentadora

El estudio menciona que los docentes de las clases tanto de yoga como estiramiento son idóneos en el tema y fueron asesorados por expertos en lumbalgia. Esto podría limitar la indicación en nuestra práctica diaria si no contamos con estas referencias a la hora de derivar a los pacientes.

\section{Ariana F. Cheng [ Servicio de Medicina Familiar y Comunitaria del Hospital Italiano de Buenos Aires. ariana.cheng@ hospitalitaliano.org.ar ]}

Cheng A. Las clases de Yoga y de Estiramiento (Stretching) son igualmente efectivas para aliviar la lumbalgia crónica. Evid Act Pract Ambul Abr-Jun 2012;15(2):50. Comentado de: Sherman K. Cherkin D. Wellman R. A Randomized Trial Comparing Yoga, Stretching, and a Self-care Book for Chronic Low Back Pain. Arch Intern Med. Oct 2011;171(22):2019-2026. PMID: 22025101.

Referencias

1. Koes B. y col. Managing low back pain. BMJ 2006;332:1430-1434. doi: 10.1136/bmj. 332.7555.1430.

2. Durante E. Lumbalgia. En: PROFAM: Programa de educación a distancia de medicina familiar y ambulatoria / Esteban Rubinstein, Miguel Zarate, Paula Carrete, editores. 2da edición, Bs. As.: Fundación MF "Para el desarrollo de la medicina familiar y la atención primaria de la salud", 2001.

3. Hayden JA, y col. Meta-analysis: exercise therapy for nonspecific low back pain. Ann Intern Med. 2005;142(9):765-775.

4. Galantino ML, y col. The impact of modified Hatha yoga on chronic low back pain: a pilot study. Altern Ther Health Med. 2004;10(2):56-59. 